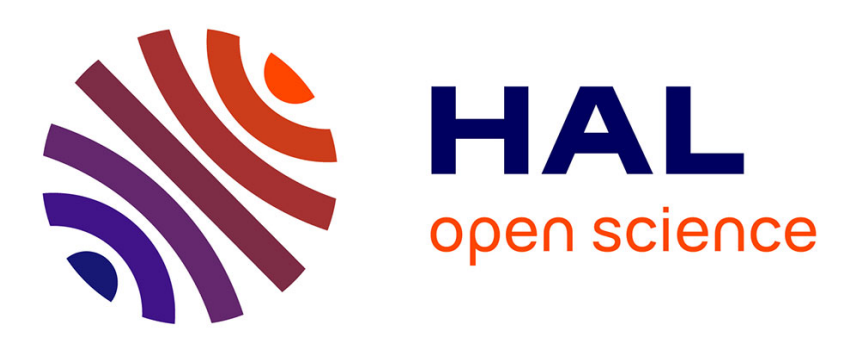

\title{
Switched reluctance machine vibration reduction using a vectorial piezoelectric actuator control
}

X. Ojeda, H. Hannoun, X. Mininger, M. Hilairet, M. Gabsi, C. Marchand, M.

\author{
Lécrivain
}

\section{- To cite this version:}

X. Ojeda, H. Hannoun, X. Mininger, M. Hilairet, M. Gabsi, et al.. Switched reluctance machine vibration reduction using a vectorial piezoelectric actuator control. European Physical Journal: Applied Physics, 2009, 47 (3), pp.1-8. 10.1051/epjap/2009106 . hal-00491504

\section{HAL Id: hal-00491504 \\ https://hal.science/hal-00491504}

Submitted on 12 Jun 2010

HAL is a multi-disciplinary open access archive for the deposit and dissemination of scientific research documents, whether they are published or not. The documents may come from teaching and research institutions in France or abroad, or from public or private research centers.
L'archive ouverte pluridisciplinaire HAL, est destinée au dépôt et à la diffusion de documents scientifiques de niveau recherche, publiés ou non, émanant des établissements d'enseignement et de recherche français ou étrangers, des laboratoires publics ou privés. 


\title{
Switched Reluctance Machine Vibration Reduction using a Vectorial Piezoelectric Actuator Control
}

\author{
Ojeda X. ${ }^{1}$, Hannoun H. ${ }^{2}$, Mininger X. ${ }^{2}$, Hilairet M. ${ }^{2}$, Gabsi M. ${ }^{1}$, Marchand C. ${ }^{2}$ and Lécrivain M. ${ }^{1}$ \\ ${ }^{1}$ SATIE, ENS Cachan, Paris XI, CNRS UMR 8029, UniverSud, 61 av President Wilson, F-94230 Cachan Cedex, France, \\ ojeda@satie.ens-cachan.fr \\ 2 LGEP, CNRS UMR 8507, SUPELEC, UPMC Univ Paris 06, Univ Paris-Sud, 11 rue Joliot-Curie, Plateau de Moulon, F-91192 \\ Gif-sur-Yvette Cedex, xavier.mininger@lgep.supelec.fr
}

Received: date / Revised version: date

\begin{abstract}
This paper deals with an original approach of the Switched Reluctance Machine (SRM) control for the purpose of reducing stator vibrations. Two combined approaches are studied in the aim of reducing the vibratory acceleration generated and thus the acoustic noise. The first one is based on a sinusoidal control of the magnetic phase current and the second one, on an optimal control of piezoelectric actuators (PZT) stuck on the SRM stator. The sinusoidal control of the magnetic phase current introduces properties on the vibratory acceleration distribution that are used to design an original actuator controller. Principles and viability of these combined vibration damping methods are deduced from theories and experiments.
\end{abstract}

PACS. 84.50. + d Electric motors - 33.20.Tp Vibrational analysis - 46.40.Ff Resonance, damping, and dynamic stability - 77.65.-j Piezoelectricity and electromechanical effects

\section{Introduction}

Switched reluctance motors exhibit complementary performances to that of classical motors. Due to a passive rotor and no need for any magnet, SRM provide an attractive alternative for high-speed applications [1], and in high surrounding temperatures. However, the noise gener- ated from this machine is greater than for other machines. A salient rotor and a rectangular current shape lead to an increase of noise emissions [2].

Many solutions have been studied in the aim of decreasing SRM noise emissions; these include adapted current shape [3], optimal stator design [2] or active control [4]. The method used in this paper is based on an active con- 
trol of piezoelectric elements. In a previous paper [5], the decrease of the SRM vibrations has been studied using a single phase SRM with a single piezoelectric phase $(2$ actuators) in the aim of validating the method. The control has been achieved with a single input single output (SISO) Positive Position Feedback (PPF) that is a classical solution in vibration problems. In order to generalize the method, this vibration reduction principle is here applied for a three phase SRM with three piezoelectric phases (6 actuators). Moreover, the current applied on the SRM is now a sinusoidal one so as to obtain a better reduction of vibrations. A sinusoidal current feeding generates a rotating magnetic field and consequently a mechanical travelling wave. From this property, the design of a new controller is realized. The controller is designed so as to generate a mechanical travelling wave that is able to decrease the resulting displacement (due to the mutual effect of magnetic and piezoelectric phases). The optimal placement and design of the PZT actuators stuck on the SRM stator are achieved with an extension of the method described in [6], [7].

This paper begins by presenting the interests of a sinusoidal current regulation of the magnetic current in comparison with a classical current regulation. An optimization of the current shape with torque maximization and vibratory level minimization focuses on the advantages of a sinusoidal current regulation. Classical current and sinusoidal regulation schemes are compared and the contribution to the vibration reduction is experimentally obtained. Then, the theory of a vectorial vibration control under a sinusoidal magnetic current control is detailed. The controller is designed in a rotating frame, allowing the use of a classical regulator. Experimental tests validate the efficiency of such kind of regulator. Theories and associated results could be extended for all kinds of three phase SRM $(12 / 8,24 / 16$, etc. $)$.

\section{Sinusoidal current regulation}

\subsection{Current shape optimization}

Up to now, the main criteria of SRM designers were the magnetic efficiency maximization and the power electronic optimization. Thus, current shape and power inverter were designed in this context; the current feeding of the SRM is then often achieved with a rectangular current shape and an unidirectional power inverter. Minimization of the active component numbers and no need of sophisticated position sensor are then the main criteria for the design.

An optimization using a genetic algorithm (NSGA II, [8]) is achieved so as to design the best current shape for a typical 6/4 SRM. This method could easily be adapted to the other SRM geometries. Two objectives are computed in order to obtain a Pareto front of optima: torque maximization deduced from the tangential force obtained by finite element simulations and Joule losses minimization. A current SRM period is thus divided in little intervals, giving 360 current samples $\left(i^{0}=i(\theta=0), i^{1}=i(\theta=\delta \theta)\right.$, $\left.i^{n}=i(\theta=n \delta \theta), \ldots\right)$. These samples are the parameters that have to be optimized, their amplitudes beeing in the range $[0 ; 1]$. 


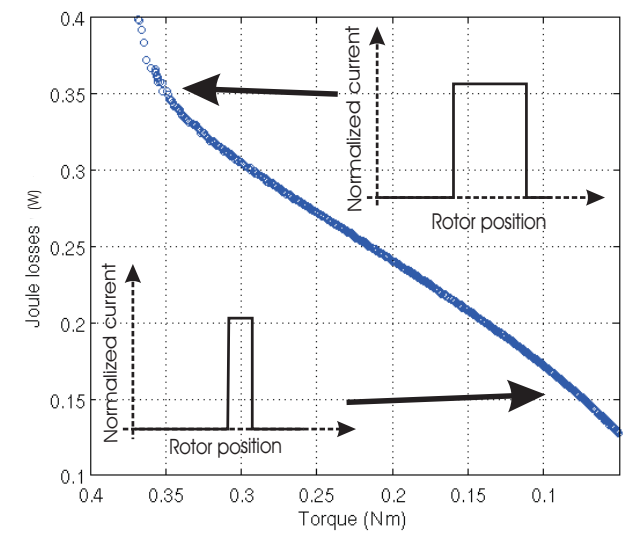

Fig. 1. Pareto front resulting from torque maximization and Joule losses minimization

As shown on figure 1, the optimal current shape is an unipolar rectangular one. The current control angle yields to obtain a compromise between the torque (i.e. maximization of the control angle) and the Joule losses (i.e. the current shape is closed to a Dirac current shape). Figure 2 represents the typical inverter used for rectangular current feeding of SRM.

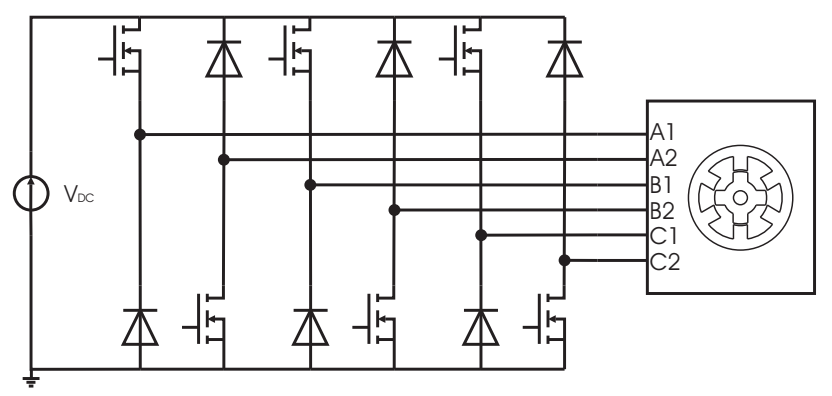

Fig. 2. Unidirectional power inverter used for rectangular current feeding

However, in low voltage applications, the voltage drop due to power diode is not allowed and active components like MOSFET or IGBT are prefered. Moreover, the noise pollution has nowadays become an important preoccupa- tion for designers. Due to a large spectrum of the magnetic force induced by the rectangular current feeding, multiple mechanical resonances could be excited, leading to an increase of the acoustic noise. The noise reduction and the bi-directional power inverter advantages have led to the development of other current shapes. Therefore, a current shape optimization with a noise criterion has been achieved: the two objectives are the torque maximization and the reduction of the normal force harmonic factor, and thus, the vibration spectrum. The previous rectangular current shape is modified in order to reduce the normal force harmonic factor as shown in figure 3 . The current

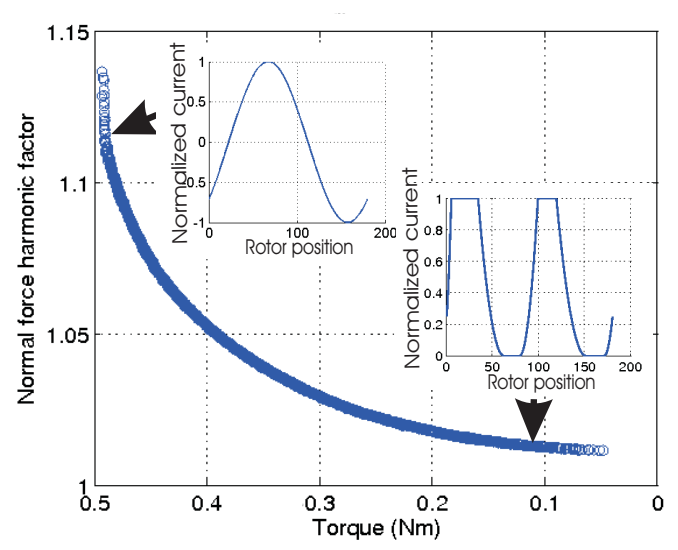

Fig. 3. Pareto front resulting from torque maximization and noise reduction

slope changes $\left(\frac{d i}{d t}\right)$ generate an important spectrum of the normal force and consequently the optimization algorithm limits these rapid changes. The more the noise reduction is important the more the current shape tends toward a sinusoidal shape. Indeed, the sinusoidal shape is the best one for the reduction of the normal force harmonic factor. 
Figure 4 represents the typical inverter used for sinusoidal current feeding of SRM.

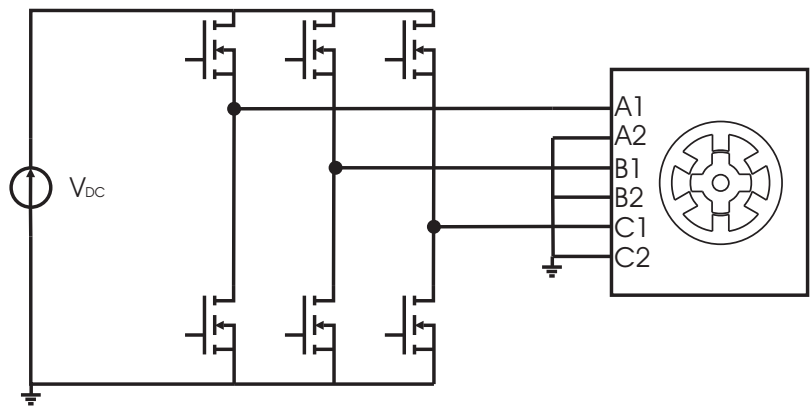

Fig. 4. Bidirectional power inverter used for sinusoidal current feeding

Unlike the inverter needed in the case of the rectangular current, it is a very classical inverter used for all kinds of drives (asynchronous, synchronous, etc.). Thus, the SRM, the position sensor and the inverter are considered as an entity similar to a brushless machine.

\subsection{Control Scheme}

The comparison between a rectangular and a sinusoidal current feeding in relation to the produced vibratory acceleration is realized with the inverter of figure 2 considering one phase feeding. The rectangular and the sinusoidal current feedings are compared using two current control schemes: an hysteresis controller (HC) and a gain-scheduling PI controller (PIv) [9], [10]. Since the phase inductance $(\mathrm{L})$ varies with rotor position $\theta$ and current $i$ (considering magnetic saturation, see figure 5), a controller that takes into consideration these variations should give better performances.

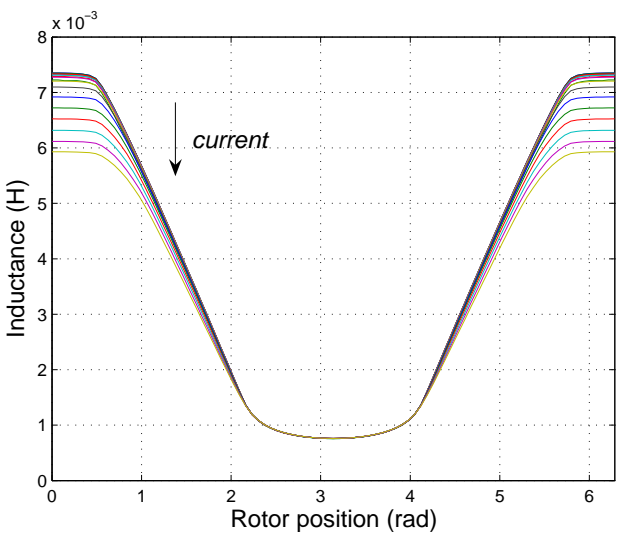

Fig. 5. Phase inductance versus current and rotor position

The adaptive PI controller is self-tuning. Its design is based on conventional PI controller concept, except that its proportional and integral coefficients $\left(K_{p}\right.$ and $\left.K_{i}\right)$ are adjusted on line as the current and the position changes. Figure 6 shows a block diagram of the proposed controller. The transfer function of the closed-loop system is given by :

$$
\frac{I^{*}(s)}{I(s)}=\frac{\frac{K_{p}}{L} s+\frac{K_{i}}{L}}{s^{2}+\left(\frac{K_{p}+R}{L}\right) s+\frac{K_{i}}{L}}
$$

where $R$ and $L$ are respectively the phase winding re-

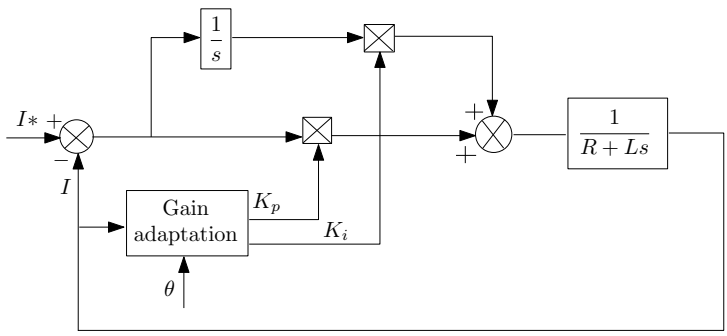

Fig. 6. Schematic of the PI controller

sistance and the phase inductance. Assuming the winding resistance is negligible (in comparison with $K_{p}$ ), the closed-loop transfer function is represented by a second 
order system:

$$
\frac{I^{*}(s)}{I(s)}=\frac{2 \xi w_{n} s+w_{n}^{2}}{s^{2}+2 \xi w_{n} s+w_{n}^{2}}
$$

where $\xi$ is the damping ratio and $w_{n}$ is the bandwidth of the closed loop system. The proportional $K_{p}$ and integral $K_{i}$ gains are computed according to equations 1 and 2 :

$$
\left\{\begin{array}{l}
K_{i}(\theta, i)=\quad L(\theta, i) w_{n}^{2} \\
K_{p}(\theta, i)=2 \xi L(\theta, i) w_{n}
\end{array}\right.
$$

An analytical modeling is adopted for the calculation of the phase inductance based on the given curves (figure 5) obtained from finite element analysis [9]. The position dependency is represented by a limited number of Fourier serie terms $(P+1)$ and the nonlinear variation with current is expressed by $N$ order polynomial functions. The phase inductance $L$, function of rotor position and phase current, can be finally written as follows :

$$
L(\theta, i)=\sum_{p=0}^{P} a_{p}(i) \cos (p \theta)
$$

with $a_{p}$ is a polynomial function of current $i$. Therefore, for a chosen controller characteristic $\left(\xi\right.$ and $\left.w_{n}\right)$, its gains $\left(K_{p}\right.$ and $\left.K_{i}\right)$ vary with the current and the position in order to maintain the same time response of the current.

\subsection{Experimental results}

All experimental tests are realized with a rotational speed of 2,000 rpm, for a $20 \mathrm{~V}$ DC link voltage, no load functioning and are reproducible in a range from 0 to 6,000 rpm. For rotational speeds greater than $6,000 \mathrm{rpm}$ with a $20 \mathrm{~V}$ DC voltage, the current control is not efficient enough due to the back EMF voltage increasing, giving a small difference between the DC link voltage and the back EMF.

Figure 7 shows a comparison between a rectangular and a sinusoidal SRM current obtained with an hysteresis control. The magnitude and the shape of the rectangular and sinusoidal spectrum are here nearly similar.

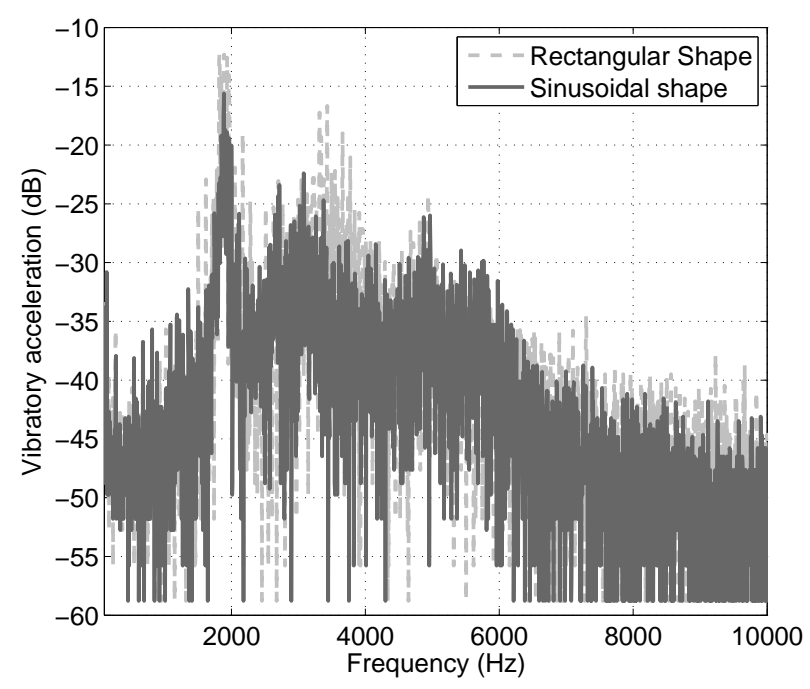

Fig. 7. Comparison between rectangular and sinusoidal feedings with hysteresis controller at 2,000 rpm

For this motor, considering these material properties and dimensions, the mode 2 resonance is the worst mode for the vibration reduction problem. It is composed by a superposition of two strains: a strain at $3 \mathrm{kHz}$ corresponding to a mode 2 in the section plane and a constant strain in the SRM active length (mode 2,0 ), and a strain at 5 $\mathrm{kHz}$ corresponding to a mode 2 in the section plane and a mode 1 in the SRM active length (mode 2,1).

Around the mode 2 resonance, a decrease of $5 \mathrm{~dB}$ is obtained with a sinusoidal shape. However, hysteresis control is not a fixed frequency regulation. A large band spectrum 
induced by this functioning excites the mode 2 resonance independently of the current shape.

Figure 8 shows a comparison between a rectangular and a sinusoidal control of the SRM current with a gainscheduling PI controller. A damping from 10 to $15 \mathrm{~dB}$ is obtained with a sinusoidal current shape on the vibration reduction point of view.

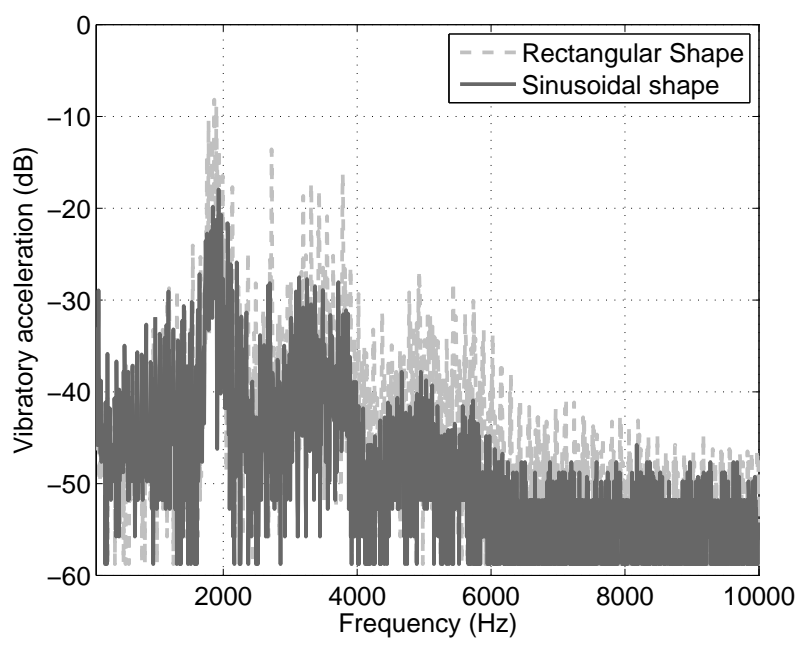

Fig. 8. Comparison between rectangular and sinusoidal feedings with gain-scheduling PI controller at 2,000 rpm

This method is less penalizing because of the single modulation frequency chosen out of mechanical resonance frequencies or multiple of these frequencies (pulse width modulation frequency at $16,000 \mathrm{~Hz}$ ).

Figure 9 resumes these results with the two sinusoidal current shapes controlled by hysteresis or gain-scheduling PI controller. A vibratory reduction from 5 to $10 \mathrm{~dB}$ and a $5 \mathrm{~dB}$ power acoustic reduction (obtained by integration over audible frequencies of the vibratory acceleration) are shown for the gain scheduling PI controller.

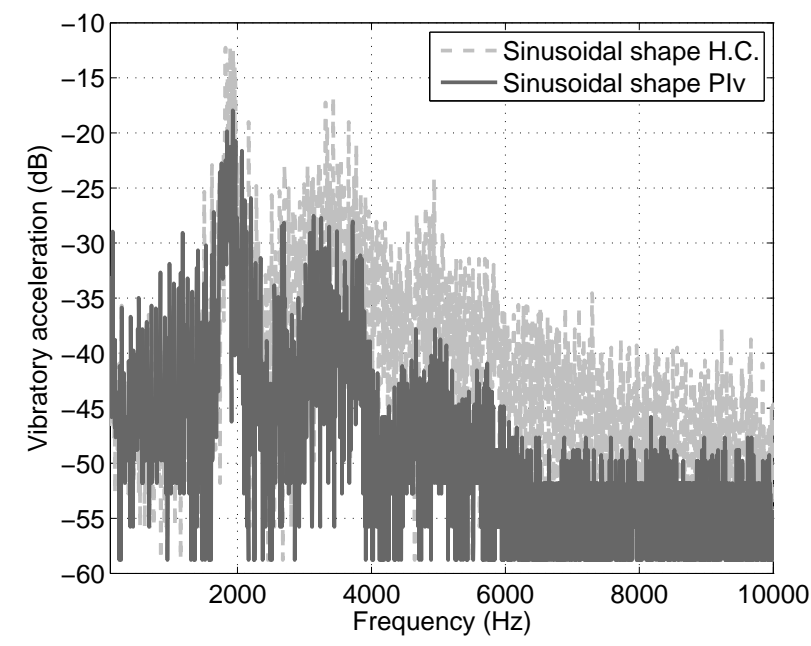

Fig. 9. Comparison between two sinusoidal feedings with hysteresis and gain-scheduling PI controller

\section{PZT actuator regulator with sinusoidal SRM current feeding}

\subsection{Vibratory acceleration created by sinus current regulator}

Section 2 has shown the interests of the SRM sinusoidal feeding for vibration reduction issue. In this section, sinusoidal currents are applied to the SRM magnetic phases. This kind of current shape applied to a magnetic phase generates a force density $\left(P_{m a g}\right)$ on the corresponding teeth of the stator [11]. It can be approximated by:

$$
P_{\text {mag }}\left(i_{\text {phase }}\right)=\frac{B^{2}\left(i_{\text {phase }}\right)}{2 \mu_{0}}=K_{\text {phase }} i_{\text {phase }}^{2}
$$

where $\mathrm{B}$ is the flux density on the surface of a teeth. Considering a sinusoidal current control of SRM, this force density can be described by:

$$
P_{\text {mag }}(t)=K_{\text {phase }} I^{2} \sin ^{2}(\omega t)
$$


The force density applied on the teeth generates a vibratory acceleration of the stator:

$$
\gamma(t, \theta)=h(t, \theta) * P_{m a g}(t)
$$

where $h(t, \theta)$ is the mechanical impulse response of the stator considered for a mode 2 mechanical resonance (the most important resonance in this application) and $\theta$ the mechanical angle between the considered position and the magnetic phase 1 .

The vibratory displacement is smaller than stator dimensions, so that the vibratory displacement can be easily deduced from the force density applied according to the elastic assumption. The force density generated by current feeding is composed of harmonics that excite the mechanical structure. Only harmonics near from mode 2 resonance frequency are considered. At last, the vibratory acceleration is deduced from the vibratory displacement by derivations:

$$
\gamma(t, \theta)=K_{\text {phase }}^{\prime} I^{2} \cos (2 \omega t) \cos (2 \theta)
$$

where $K_{\text {phase }}^{\prime}$ is deduced from equations 6 and 7 .

Equation (8) determines the mechanical effect of one magnetic phase on the stator. This equation is easily extended for 3 magnetic phases placed with a mechanical angle of $\frac{2 \pi}{3}$ between each other and currents with an electric phase of $\frac{2 \pi}{3}$ between each other. So, the total vibratory acceleration $\gamma_{M A G}$ can be computed by:

$$
\gamma_{M A G}(t, \theta)=\frac{3}{2} K_{\text {phase }}^{\prime} I^{2} \cos (2 \omega t-2 \theta)
$$

The three magnetic phases generate a travelling wave of vibratory acceleration which depends on position and time for a mode 2 strain at the pulsation $2 \omega$, figure 10 .

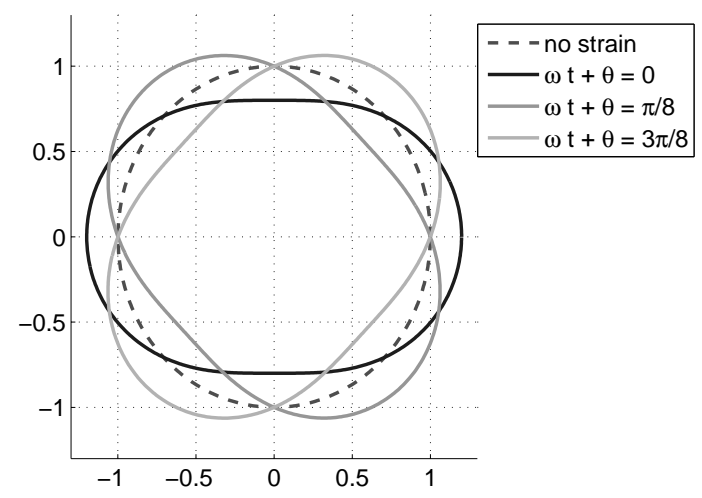

Fig. 10. Polar representation of the vibratory acceleration field for different values of $\omega t+\theta$

\subsection{Design and placement of PZT actuators}

The design and the placement of the piezo-ceramic (Lead Titano-Zirconate, PZT) actuators are realized considering material properties and dimensions, the resonance modes and the required actuator number [6]. However, in this particular case, actuators have to be able to generate a travelling wave of vibratory acceleration (or strain). Thus, the design of actuators is obtained by maximization of the generated strain, and the placement in order to get a travelling wave. With respect to geometry symmetries, 3 pairs of actuators are designed (length $40 \mathrm{~mm}$, width 12 $\mathrm{mm}$ and thickness $2 \mathrm{~mm}$ ) and placed with a mechanical angle of $\frac{2 \pi}{3}$ between each other, figure 11 .

Due to the actuator dimensions and mechanical properties (Young modulus), modifications of the stator stiffness and mechanical resonances are neglected. This assumption has been verified by finite element simulations.

PZT actuators are placed so as to have an opposition phase between the vibratory acceleration of the PZT actuators $\mathrm{A}$ and the vibratory acceleration from the magnetic 


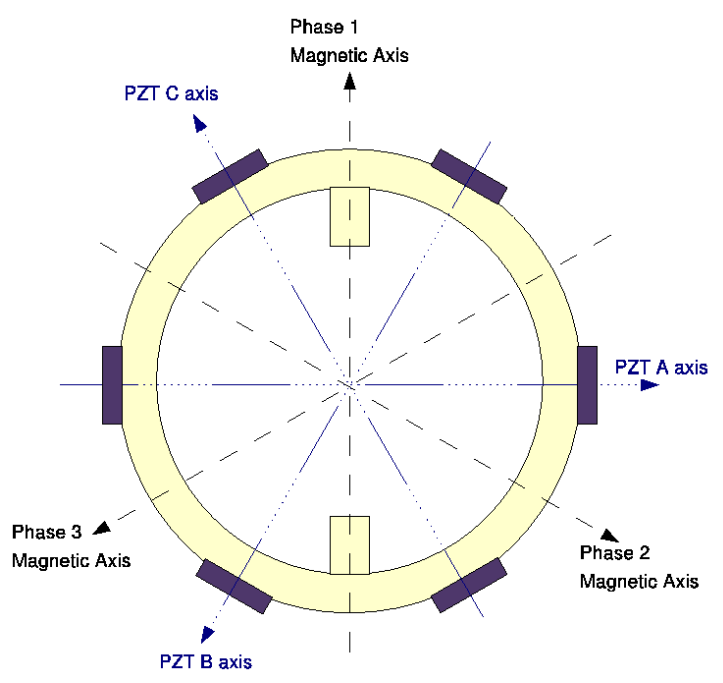

Fig. 11. Simplified SRM scheme

phase 1 (and so on for the PZT actuators B and the magnetic phase 2 , etc.). Thus, considering a mode 2 displacement (anti-nodes of displacement at $\theta=\left\{0 ; \frac{\pi}{2} ; \pi ; \frac{3 \pi}{2}\right\}$ ), the mechanical angle between the PZT actuators A and the magnetic phase 1 is $\frac{\pi}{2}$.

\subsection{PZT actuator regulator based on travelling wave}

\section{principle}

In order to reduce the vibration generated by the SRM functioning, PZT actuators are stuck on the SRM stator. The aim of these actuators is to create a stress and thus a strain that added to the magnetic one reduces the resulting strain and consequently, the vibratory acceleration. One PZT actuator stuck on the SRM stator generates a vibratory displacement according to the Hooke's law [12]:

$$
d_{P Z T}(t)=K_{P Z T} V_{P Z T}(t)
$$

where $V_{P Z T}(t)$ is the voltage applied to the PZT actuator and $K_{P Z T}$, the piezoelectric conversion coefficient which depends on PZT properties $\left(d_{31}\right.$, etc. $)$ and actuator dimensions. According to section 3.1, the vibratory acceleration is computed by:

$$
\gamma_{P Z T}(t, \theta)=K_{P Z T}^{\prime} V_{P Z T}(t) \cos \left(2 \theta+\theta_{0}\right)
$$

with $\theta_{0}$, the actuator position measured from the first magnetic phase. $K_{P Z T}^{\prime}$, is a mechanical parameter which depends on the piezoelectric parameter $K_{P Z T}$ and on the mechanical resonance. In order to obtain the same vibratory acceleration as in the magnetic case (equation 8), the applied voltage has to be $V_{P Z T}(t)=V \cos \left(2 \omega t+\phi_{0}\right)$ with $\phi_{0}=\theta_{0}+\delta \phi, \delta \phi$ beeing the electric phase of the actuator voltage (measured since the magnetic axis 1 ). Thus, the vibratory acceleration is computed by:

$$
\gamma_{P Z T}(t, \theta)=K_{P Z T}^{\prime} V \cos \left(2 \omega t+\theta_{0}+\delta \phi\right) \cos \left(2 \theta+\theta_{0}\right)
$$

Considering the 3 pairs of actuators, the total vibratory acceleration due to the actuators is:

$$
\gamma_{P Z T}(t, \theta)=\frac{3}{2} K_{P Z T}^{\prime} V \cos (2 \omega t-2 \theta+\delta \phi)
$$

Equation 13 shows that 3 pairs of actuators with an appropriate control $(V$ and $\delta \phi)$ generate a travelling wave of vibratory acceleration like 3 magnetic phases.

2 accelerometers are placed so as to measure the vibratory accelerations, $\gamma_{f_{1}}$ and $\gamma_{f_{2}}$, on the magnetic phase $1(\theta=0)$ and $2\left(\theta=\frac{2 \pi}{3}\right)$. The vibratory acceleration $\gamma_{f_{3}}$ of the magnetic phase $3\left(\theta=-\frac{2 \pi}{3}\right)$ is deduced from the two others, assuming $\gamma_{f_{1}}+\gamma_{f_{2}}+\gamma_{f_{3}}=0$. Without control of PZT voltage $(V=0)$, the vibratory acceleration complex vector due to magnetic phenomena can be defined as 
follow:

$$
\begin{gathered}
\gamma_{f_{1}}+\underline{a} \gamma_{f_{2}}+\underline{a}^{2} \gamma_{f_{3}}=\frac{3}{2} K_{\text {phase }}^{\prime} I^{2} e^{j 2 \omega t}=\underline{\gamma}_{M A G} \\
\underline{\gamma}_{M A G}=\gamma_{f} e^{j \phi_{f}} e^{j 2 \omega t}
\end{gathered}
$$

where $\underline{a}$ is a complex operator $\left(\underline{a}=e^{j \frac{2 \pi}{3}}\right)$. In the same way, without current control $(I=0)$, the vibratory acceleration complex vector due to PZT actuators can also be defined as:

$$
\begin{gathered}
\gamma_{f_{1}}+\underline{a} \gamma_{f_{2}}+\underline{a}^{2} \gamma_{f_{3}}=-\frac{3}{2} K_{P Z T}^{\prime} V e^{j(2 \omega t+\delta \phi)}=\underline{\gamma}_{P Z T} \\
\underline{\gamma}_{P Z T}=\gamma^{*} e^{j \phi^{*}} e^{j 2 \omega t}
\end{gathered}
$$

The total vibratory acceleration is described by the sum of the two previous equations:

$$
\underline{\gamma}_{f}=\underline{\gamma}_{M A G}+\underline{\gamma}_{P Z T}
$$

Figure 12 represents a vectorial representation of the acceleration vectors in the rotating frame.

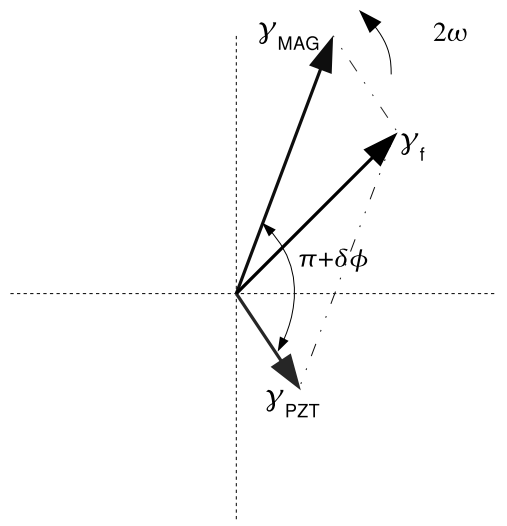

Fig. 12. Vectorial scheme of $\gamma_{M A G}, \gamma_{P Z T}$ and $\gamma_{f}$

The principle of reducing the vibratory acceleration generated is to cancel the resulting vibratory acceleration. General controllers like Positive Position Feedback $(\mathrm{PPF})$ are often used in vibratory damping problem [13].
However, the knowledge of the vibratory acceleration field allows the design of a more simple controller. The new vectorial controller is designed in a frame which rotates at the speed $2 \omega$. The problem is then reduced at a constant value control of the complex vibratory acceleration magnitude. Thus, equations 15 and 17 are multiplied by a rotation factor $e^{-2 \omega t}$, and a control scheme is deduced from these equations, figure 13:

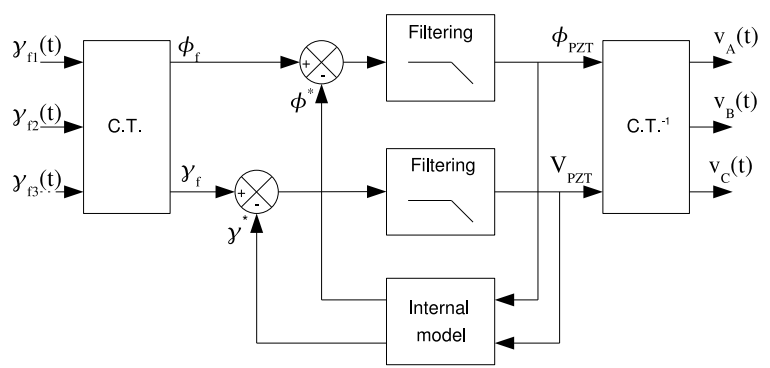

Fig. 13. Controller scheme using vector field property

An internal model control [14] is chosen for the regulation in the rotating frame. Its simplicity and robutness are the main design criteria. The principle of this controller is to control values of the complex magnitude $\gamma^{*}$ and electric phase $\phi^{*}$ of the PZT actuators in order to synchronize the PZT actuator travelling wave with the travelling wave due to the electrical feeding $\left(\gamma^{*}=\gamma_{f}\right.$ and $\left.\phi^{*}=\phi_{f}\right)$. The filtering blocks represent the stabilizing filter of the closed loop. The internal model bloc represents a matrix transfer gain that transforms the complex PZT actuator voltage magnitude and phases into the complex magnitude and phase of the vibratory acceleration, see equation 17. C.T. and C.T. ${ }^{-1}$ blocks represent respectively the complex tranformation and the inverse complex 
tranformation that transform three temporal signals into a complex magnitude and its associated phase.

\subsection{Simulations of the vectorial controller}

The simulation model considers only one mechanical resonance frequency (mode 2 resonance) at 5,000 Hz. From the current applied on the SRM, the magnetic forces are deduced with equation 5 . Then, the vibratory acceleration is computed according to equation 7 . In order to represent the actual functioning of the SRM (no-deterministic mechanical and aerodynamic noise [15]), three uncorrelated white noise representing $10 \%$ of the current magnitude have been added to each current. Figure 14 shows the three currents applied on the SRM magnetic phases and the vibratory acceleration computed from these currents. Using equation 14, the complex vibratory acceler-
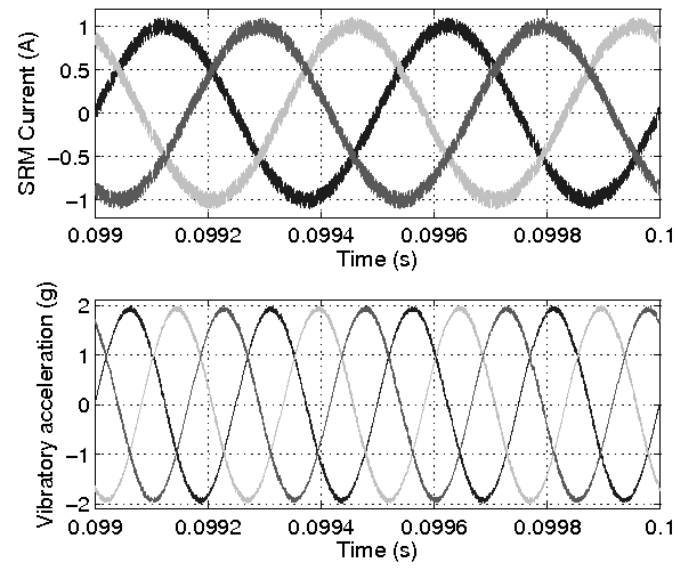

Fig. 14. Currents and corresponding vibratory accelerations on the SRM

ation magnitude is deduced, Figure 15. The simulation scheme is based on figure 13. Figure 16 shows a compari-

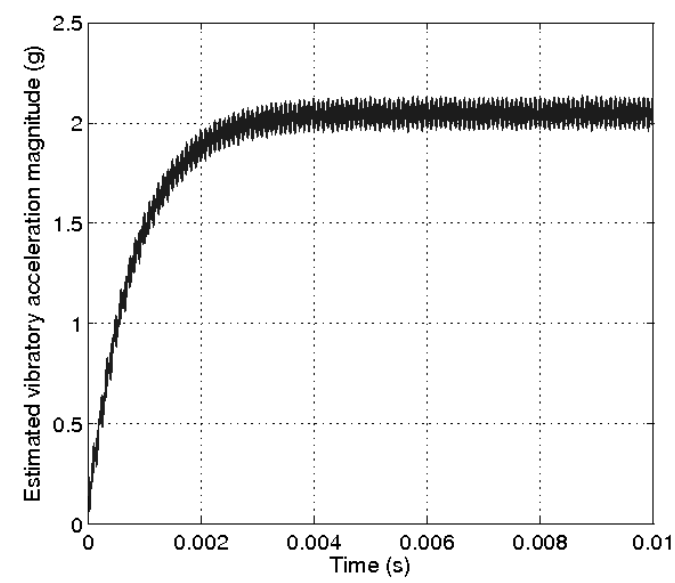

Fig. 15. Estimated vibratory acceleration magnitude

son between accelerations in open and closed loop in time domain for the magnetic phase 1 . The voltage applied to

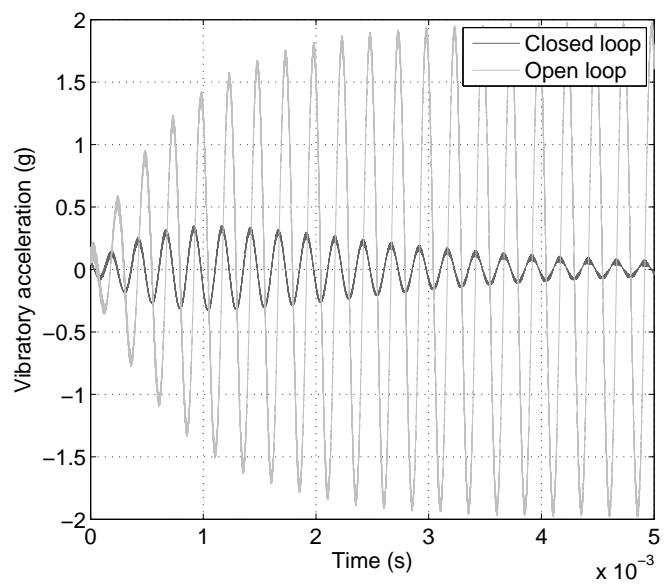

Fig. 16. Time simulation for the vibratory acceleration of the magnetic phase 1

the PZT actuators so as to obtain the vibratory damping of figure 16 has a $2 \mathrm{~V}$ magnitude at the mode 2 resonance frequency. For piezoelectric actuators, this voltage magnitude has a low level, and operational amplifiers are sufficient to realize the controller. As seen on figure 16, an important vibratory acceleration damping is obtained. 
These simulations validate the principle of the vectorial controller.

\subsection{Experimental results for vectorial active damping}

The test bench, shown in figure 17, is composed by the $6 / 4$ SRM (10,000 nominal speed and 0.2 Nm nominal torque), with an $40 \mathrm{~mm}$ active length and a $60 \mathrm{~mm}$ diameter. A PM machine in the same shaft is used as a position sensor. According to figure 11, 6 PZT actuators are stuck on the external surface of the stator and controlled by a Dspace platform (control voltage between $\pm 10 \mathrm{~V}$ ). The

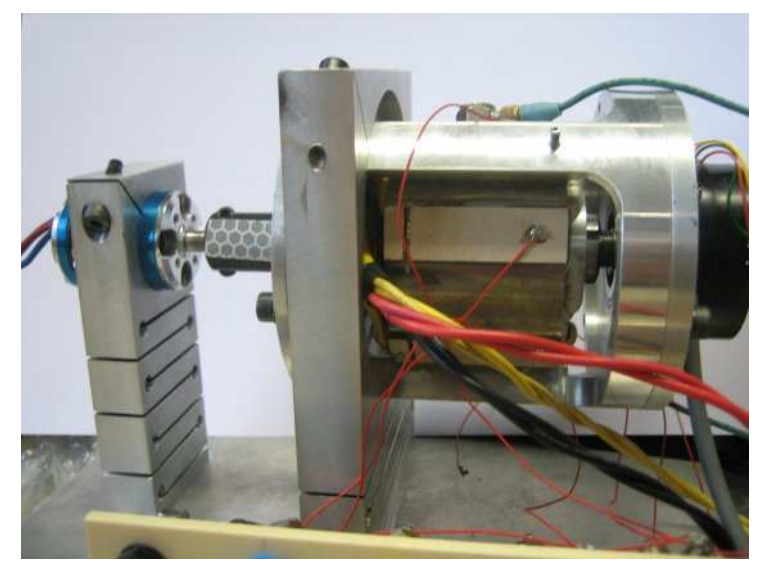

Fig. 17. Experimental test bench for vibration damping

three magnetic phases are controlled by a sinusoidal current for a rotational speed of 5,000 rpm. At this rotational speed the main source of vibration is the magnetic one. The comparison between open loop and closed loop is presented on figure $18.10 \mathrm{~dB}$ vibration damping are obtained around mode 2 resonance frequencies $(3 \mathrm{kHz}$ and 5 $\mathrm{kHz}$ ), as the simulation results reveal. However, the gain induces by the controller increases from $5 \mathrm{~dB}$ the vibration around $10 \mathrm{kHz}$. On figure 19, the method is tested in

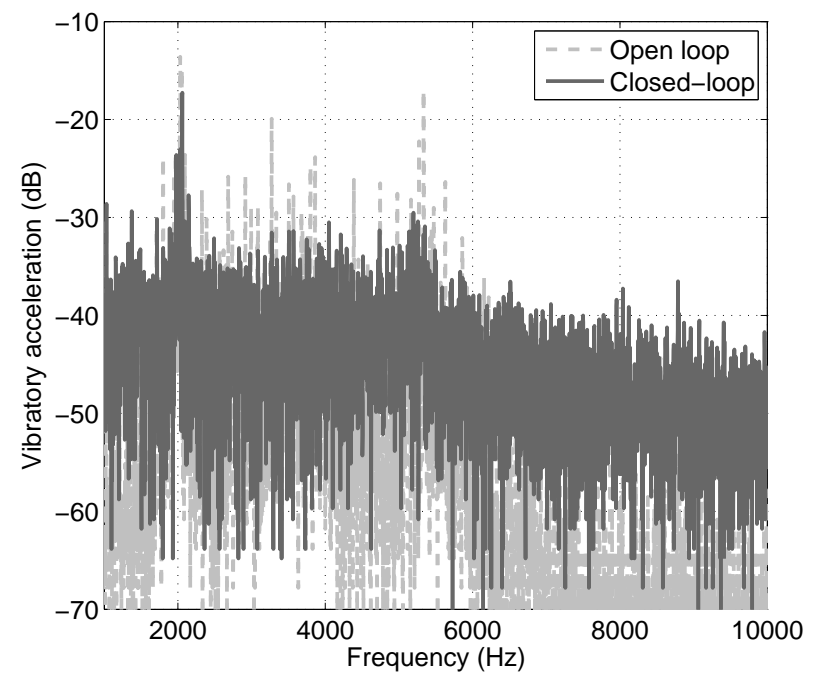

Fig. 18. Experimental results at 5,000 rpm for a magnetic excitation

the worst case: the PM machine is used as a motor and no current is applied on the SRM. Thus, the only SRM vibration sources are the mechanical and aerodynamic ones. On this figure, the vibratory acceleration around the mode

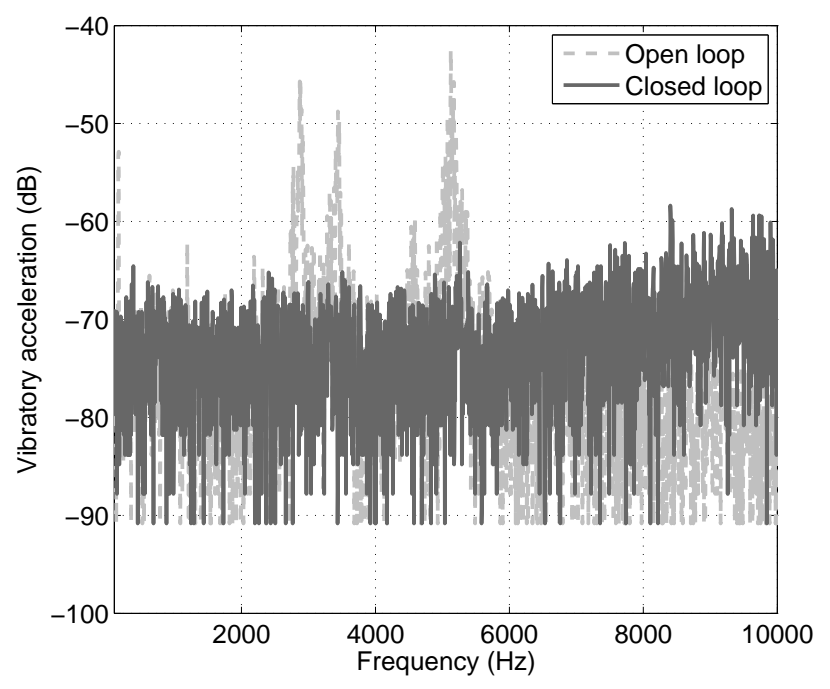

Fig. 19. Experimental result at $10,000 \mathrm{rpm}$ for an aerodynamic and mechanical excitations

2 is totally reduced. However, an increase of $5 \mathrm{~dB}$ of the 
acceleration level is noticed for high frequencies. This prin-

ciple of reduction is totally operative in a large rotational speed range, both low and high speeds, and allows an efficient reduction of vibration level around mechanical resonance frequencies. Moreover, the power consumption of each piezoelectric actuator is lower than $1 \mathrm{~mW}$.

\section{Conclusion}

This article has presented an original controller for PZT actuators based on a vectorial representation of the generated vibratory acceleration. This method offers an attractive alternative to other compensation damping techniques which do not use travelling wave properties of the vibratory acceleration. In particular, it provides the possibility to target the resonance to damp by considering an awkward resonance mode and its corresponding strain. An experimental comparison of two current shapes with two different controllers highlights the benefits of a sinusoidal current feeding for SRM. Moreover, experimental results of active damping validate this principle with sinusoidal current feeding of the SRM.

Ongoing works aim at enhancing the effectiveness of active damping techniques, and at their implementation on a three-phase SRM having several vibration modes in the audible spectrum. Furthermore, this theory has to be generalized for all kinds of current feedings.

\section{References}

1. R. Cardenas, R. Pena, M. Perez, J. Clare, G. Asher and P. Wheeler, Power smoothing using a switched reluctance machine driving a flywheel, IEEE transactions on energy conversion, Vol. 21 N. 1, pp. 294-295, march 2006.

2. M. Besbes, C. Picod, F. Camus and M. Gabsi, Influence of stator geometry upon vibratory behaviour and electromagnetic performances of switched reluctance motors, IEE proceedings Electric Power Applications, Vol. 145, pp. 462-468, September 1998

3. W. Pengov, J. R. Hendershot Jr and T. J. E. Miller, A new low-noise two-phase switched reluctance motor, IEEE International Electric Machines and Drives Conference, May 2005 .

4. J. P. Lecointe, R. Romary, and J. F. Brudny, Analysis and active reduction of vibration and acoustic noise in switched reluctance motor, Inst. Electr. Eng. Electr. Appl., Vol. 151, pp 725-733, 2004

5. X. Ojeda, X. Mininger, M. Gabsi and M. Lécrivain, Noise reduction using piezoelectric active control on high speeds switched reluctance drives, IAS meeting, September 2007.

6. X. Ojeda, X. Mininger, M. Gabsi and M. Lécrivain, Noise cancellation of $6 / 4$ switched reluctance machine by piezoelectric actuators: Optimal design and placement using genetic algorithm, 4th IET Conference on Power Electronics, Machines and Drives PEMD, York, UK, April 2008.

7. M. Gabsi, X. Mininger, Ecole Normale Supérieure de Cachan and CNRS, patent PCT/FR05/02205, October 2005.

8. K. Deb, P. Amrit, A. Sameer and T. Meyarivan, A fast and elitist multi-objective genetic algorithm: NSGA-II, IEEE Trans. Evol. Computat., Vol. 6, pp. 182-197, April 2002. 
9. H. Hannoun, M. Hilairet and C. Marchand, Analytical modeling of switched reluctance machine including saturation, IEEE International Electric Machines and Drives IEMDC, Antalya, Turkey, 2007.

10. H. Hannoun, M. Hilairet and C. Marchand, Gainscheduling PI current controller for a Switched Reluctance Motor, IEEE International Symposium on Industrial Electronics ISIE, Vigo, Spain, June 2007.

11. R.S. Colby, F.M. Mottier and T.J.E. Miller, Vibration modes and acoustic noise in a four phase switched reluctance motor, IEEE Transactions on Industry applications, Vol. 32, pp. 1357-1364, 1996.

12. IEEE Standard on Piezoelectricity 1988, ANSI/IEEE Std. $176-1987$.

13. S. O.R. Moheimani, B. J.G. Vautier and B. Bhikkaji, Experimental implementation of extended multivariable PPF control on an active structure, IEEE Transactions on Control Systems Technology, Vol. 14, pp. 443-455, May 2006.

14. C. E Garcia and M. Morari, Internal model control. A unifying review and some new results, Industrial \& Engineering Chemistry Process Design and Development, Vol. 31 N. 2, pp. 208-323, 1982.

15. J. O. Fiedler, K. A. Kasper and R. W. De Doncker, Acoustic Noise in Switched Reluctance Drives: An Aerodynamic Problem?, IEEE International Electric Machines and Drives Conference, May 2005. 